\title{
3. AN ESTIMATE OF HEAT FLOW ON THE METEOR RISE, SITE 7041
}

\author{
D. C. Nobes, ${ }^{2}$ J. Mienert,${ }^{3}$ C. J. Mwenifumbo, ${ }^{4}$ and J. P. Blangy ${ }^{5}$
}

\begin{abstract}
Heat-flow determinations require more than one reliable temperature measurement to obtain an estimate of the temperature gradient and, subsequently, the heat flow. Two temperature readings were taken on ODP Leg 114, both in Hole 704B. One of these readings appears to be reliable, but the other may not be valid. We can try to estimate a temperature gradient on the basis of these two points alone, or we may try to estimate the temperature from the induction $\log$ resistivity and the laboratory-measured porosity using a modified Archie's law. Using the two temperature measurements, the temperature gradient is $20 \pm 2 \mathrm{mK} / \mathrm{m}$ and the computed heat flow is $32 \pm 6 \mathrm{~mW} / \mathrm{m}^{2}$. Alternatively, we can use the one reliable temperature measurement to calibrate the temperature derived from the resistivity and porosity. The temperature and heat flow computed for individual units can be different and depend on the shape factor used in the modified Archie's law. The temperature gradient obtained from the resistivity and porosity is $38 \pm 4 \mathrm{mK} / \mathrm{m}$ and the average heat flow is $60 \pm 13 \mathrm{~mW} / \mathrm{m}^{2}$, which is consistent with the age of the Meteor Rise. These values are also consistent with the heat flow that is computed when we assume a simple linear temperature gradient from the seafloor through the sediment section.
\end{abstract}

\section{INTRODUCTION}

Geothermal measurements-the temperature gradient, thermal conductivity, and heat flow-are important tectonic parameters. The heat flow decreases systematically with age, and deviations from this decrease may be diagnostic of prolonged or renewed tectonic activity. Changes in heat flow with depth can also be indicative of fluid circulation within the seafloor. Thus, the heat flow, incorporating the thermal conductivity and temperature gradient, can be a powerful tectonic parameter.

Traditionally, heat flow is determined by taking a number of temperature and thermal-conductivity measurements across a range of depths and computing the heat flow as the product of the temperature gradient and the thermal conductivity. The probe commonly used for the Deep Sea Drilling Project (DSDP) and the Ocean Drilling Program (ODP) is the Uyeda-Kinoshita temperature probe, also called the Uyeda probe, which has been described by Yokota et al. (1979). Hyndman et al. (1987) reviewed DSDP geothermal measurements.

Unfortunately, we do not always have good temperature readings or good depth coverage. An alternative approach is to use the porosity and electrical resistivity to estimate the temperature, and hence the temperature gradient, and ultimately to obtain an estimate of the heat flow. Provided that we carefully analyze our error bounds, we can derive a meaningful value for the heat flow. These underlying ideas were used by Nobes et al. (1986) to derive estimates of the temperature

\footnotetext{
${ }^{1}$ Ciesielski, P. F., Kristoffersen, Y., et al., 1991. Proc. ODP, Sci. Results, 114: College Station, TX (Ocean Drilling Program).

2 Department of Earth Sciences, Department of Physics, and Quaternary Sciences Institute, University of Waterloo, Waterloo, Ontario, Canada N2L $3 \mathrm{G} 1$.

${ }^{3}$ GEOMAR, Forschungszentrum der Christian-Albrechts-Universität zu Kiel, D-2300 Kiel, FRG.

${ }_{4}$ Terrain Sciences Division, Geological Survey of Canada, 601 Booth Street, Ottawa, Ontario, Canada K1A 0E8.

${ }^{5}$ Department of Geophysics, Stanford University, Stanford, CA 94306 (Present address: Unocal Science and Technology, 376 S. Valencia Ave., Brea, CA 92621).
}

profile from surface heat-flow and resistivity soundings. The pore-fluid resistivity depends inversely on the temperature of seawater for a temperature range of $0^{\circ}$ to $300^{\circ} \mathrm{C}$ (Quist and Marshall, 1968). Because the resistivity of the formation depends on the pore-fluid resistivity and the porosity through Archie's law, or some modified form of Archie's law, then from our knowledge of the porosity and resistivity we can, in principle, derive the temperature.

We explore both of the procedures outlined in the preceding in this paper. We suggest that while the error bounds are large, the technique of using the resistivity and porosity profiles to estimate the heat flow is viable and in this case yields a reliable estimate of the heat flow.

\section{DIRECT TEMPERATURE MEASUREMENTS}

On ODP Leg 114, only two temperature measurements were obtained, both in Hole 704B on the Meteor Rise (Fig. 1). Site 704 is located in a basin filled with a thick sediment sequence on top of the Meteor Rise (Fig. 2). The measurements were taken using the Uyeda temperature probe at depths of 403.7 and $481.7 \mathrm{~m}$ below seafloor (mbsf). The probe is used through the drill string and is inserted into the formation ahead of the drill bit. The thermistor on the probe records the resistance, which is recorded as a time series. The calibration of the thermistors allows us to convert the resistance to temperature. The probe is allowed to come to equilibrium in the formation, so that we may obtain an accurate estimate of the formation temperature. This equilibrium may be disturbed by a number of factors. The formation may be indurated and may fracture when the probe is inserted, allowing colder water from above the formation to flow in around the probe. The probe may not be completely inserted or may be prematurely removed. The identity of the thermistors used may have been in error, so the calibration may be in question. The probe may also break. All of these factors affect the readings and may yield unreliable results.

The temperature records are shown in Figure 3. We attempted to allow the probes to come to equilibrium with the formation. The temperature at $403.7 \mathrm{mbsf}$ was $21.87^{\circ} \mathrm{C}$ (Fig. 


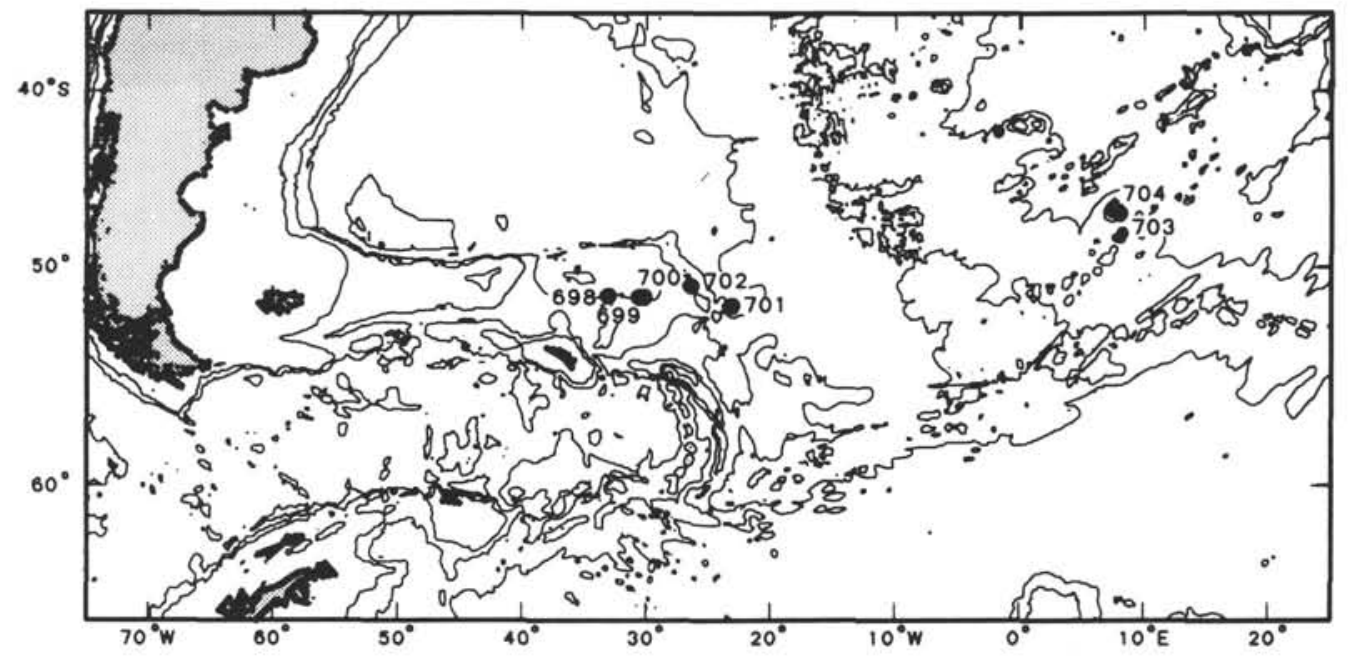

Figure 1. Bathymetric chart of the subantarctic South Atlantic showing the location of Site 704 and other Leg 114 sites. Contour interval $=1500 \mathrm{~m}$. (From Shipboard Scientific Party, 1988b.)

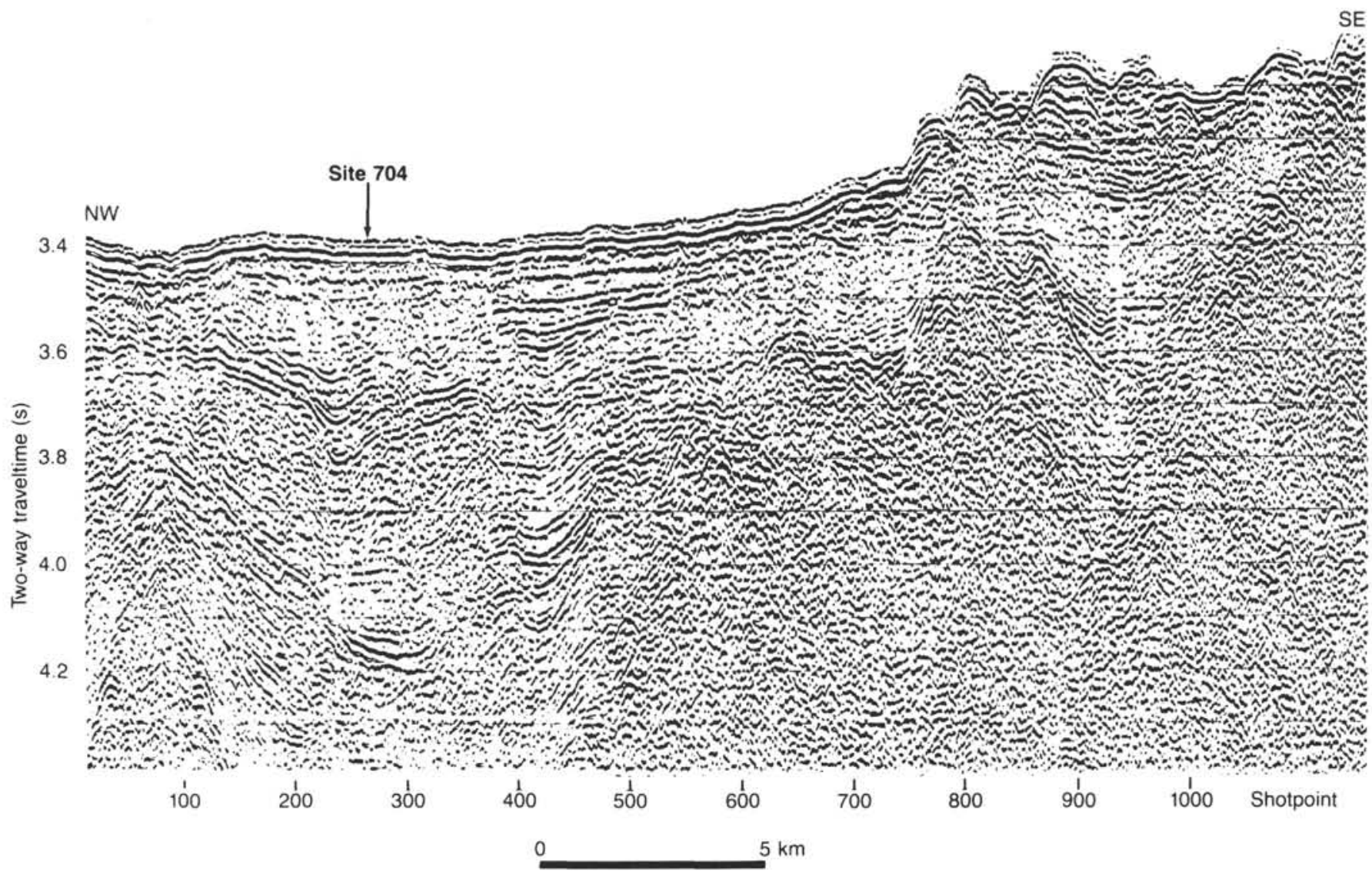

Figure 2. JOIDES Resolution single-channel seismic-reflection profile with the general location of Site 704. (From Shipboard Scientific Party, 1988b.)

$3 \mathrm{~A})$, a value that appears to be stable and reliable given the flatness of the temperature curve just before withdrawal. The seafloor temperature, the temperature at the mud line, was not well established, but was approximately $2^{\circ} \mathrm{C}$. The temperature at $481.7 \mathrm{mbsf}$ was approximately $23.4^{\circ} \pm 0.2^{\circ} \mathrm{C}$, but this value was not stable. A lower value was obtained between 40 and 50 min (Fig. 3B), possibly as a result of cooling by circulation. A second attempt to put the probe deep into the sediments while maintaining low circulation was successful but lasted only a few minutes; thus the probe may not have come completely to equilibrium. An attempt to use the Uyeda probe at $432.2 \mathrm{mbsf}$ failed when the thermistor broke.

Using the temperature readings as recorded, the temperature gradient across the depth range 403.7 to 481.7 mbsf was $20 \pm 2 \mathrm{mK} / \mathrm{m}$. If we instead use only the value for $403.7 \mathrm{mbsf}$ in conjunction with an estimate of $2^{\circ} \mathrm{C}$ for the seafloor tem- 


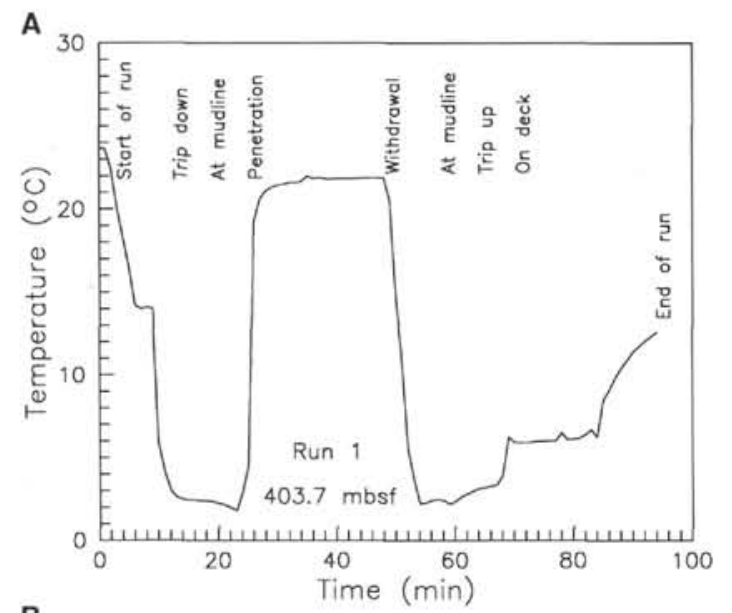

B

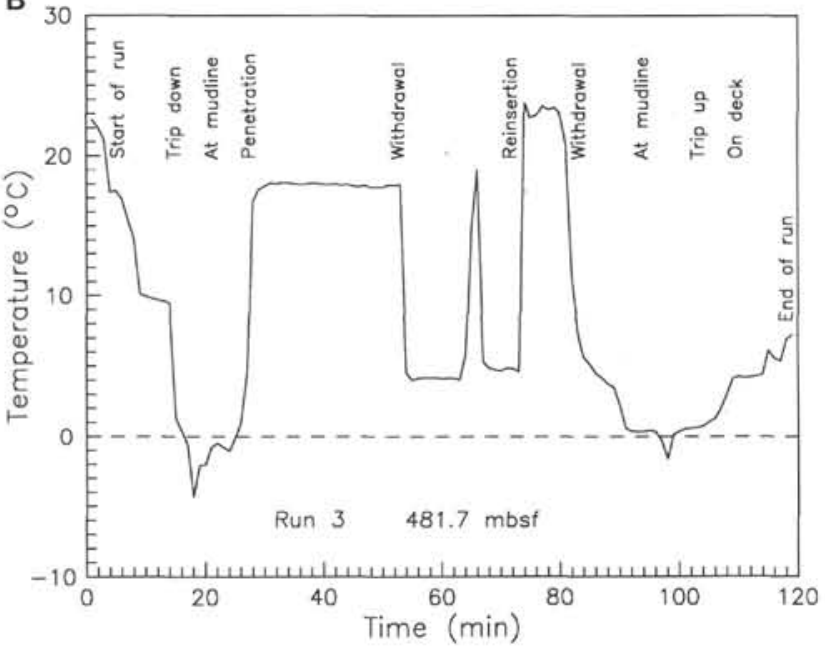

Figure 3. Plot of the successful temperature runs in Hole 704B. Each run is labeled with the run events (e.g., "at mud line" indicates that the probe was at the seafloor). A. First temperature probe run, at 403.7 mbsf. A stable value of $21.87^{\circ} \mathrm{C}$ is reached between 40 and 50 min after the start of the run and about 10 to $15 \mathrm{~min}$ after sediment penetration. The seafloor temperature is not well established, but is about $2^{\circ} \mathrm{C}$. B. Third temperature probe run, at $481.7 \mathrm{mbsf}$. The probe did not penetrate well or it was affected by circulation over the 30 - to 50 -min time interval. The result from the reinsertion yielded a potentially more representative, though less well-resolved, temperature near the 80 -min mark.

perature, the gradient is $49 \mathrm{mK} / \mathrm{m}$. These values will be used for our subsequent heat-flow computations.

\section{TEMPERATURE FROM RESISTIVITY AND POROSITY}

Alternatively, we can use the two temperature measurements to estimate the pore-fluid resistivity. By using the porosity and electrical resistivity in a modified Archie's law of the form

$$
\rho=\rho_{w} \varphi^{-n}
$$

we may compute the shape factor $n$, where $\varphi$ is the porosity, $\rho$ is the resistivity, and $\rho_{w}$ is the pore-fluid resistivity. Equation (1) is valid in the absence of clay. Mendelson and Cohen (1982) have shown that equation (1) is sufficient to characterize the resistivity-porosity relationship, and additional empir- ical factors and constants are extraneous. The shape factor varies from 1.5 to 2.5 and is dependent on the lithology. Estimates of $n$ from experiments conducted by Jackson et al. (1978) have ranged from 1.5 for spherical grains (e.g., sand) to 2.0 for platy grains (e.g., clay). Values greater than 2 have been estimated for cracked and fractured rocks and indurated sediments (Drury and Hyndman, 1979). Given measurements of the resistivity, porosity, and temperature, we may estimate the shape factor.

The resistivity can be obtained from one of three separate geophysical logs (Fig. 4). The spherically focused laterlog (SFLU) yields the resistivity close to the borehole and is most affected by variations in the borehole size, the fluid in the borehole, and the invasion of drilling fluid into the formation through the borehole wall. The medium induction $\log$ (ILM) and the deep induction log (ILD) both use electromagnetic induction methods to obtain estimates of the formation resistivity. The ILM has a depth of penetration of about 60 to 120 $\mathrm{cm}$, whereas the ILD has a depth of penetration of about 3 to $3.6 \mathrm{~m}$ (Shipboard Scientific Party, 1988a). The ILD thus yields the estimate of the resistivity most representative of the formation. We can see, however, that the SFLU, ILM, and ILD profiles are all quite similar (Fig. 4), and the correlations are high; the correlation coefficient between the ILM and the ILD is $r=0.91$. The ILM and ILD could not be distinguished if the profiles were not plotted using offset scales. The ILD resistivity was used in our subsequent analyses.

The porosity (Fig. 4) is the porosity determined in the laboratory, as outlined in Boyce (1976), in the "Explanatory Notes" (Shipboard Scientific Party, 1988a), and in detail in Nobes, Mienert, and Dirksen (this volume). The carbonate content profile is plotted alongside the porosity. The resistivity in carbonate-rich sediments depends largely on the porosity, the salinity, and the temperature of the formation. The porosity profile thus mirrors the resistivity profiles. Higher porosity and lower resistivity occur in the interval from about 220 to about 250 mbsf (lithostratigraphic Subunit $\mathrm{IC}_{2}$ ). The carbonate content is low, and the gamma-ray log (not shown) has a slightly elevated count rate, indicative of a slightly higher clay content. Clays generally have higher water content and lower resistivity. Subunit $\mathrm{IC}_{2}$ has been identified as an ash-bearing clayey diatom ooze (Shipboard Scientific Party, 1988b).

The pore-fluid resistivity depends inversely on the temperature and the salinity. If the pore fluid is seawater with salinity close to $3.5 \%$, then the pore-fluid resistivity is simply

$$
\rho_{w}=1 /(3+T / 10) \text {, }
$$

where $T$ is the temperature in ${ }^{\circ} \mathrm{C}$ (e.g., Von Herzen et al., 1983). If we know the temperature, and if the salinity is close to $3.5 \%$, then we may use the porosity and conductivity to determine the shape factor, $n$. The pore-fluid salinity at Site 704 was $3.4 \%$ to $3.5 \%$ (Shipboard Scientific Party, 1988b), and equation (2) is valid. By rearranging equation (1), we obtain the shape factor as

$$
n=\left(\log \rho_{w}-\log \rho\right) / \log \varphi
$$

The temperature at $403.7 \mathrm{mbsf}$ yields a pore-fluid resistivity of $0.1928 \mathrm{ohm}-\mathrm{m}$. We do not have values of the resistivity or porosity at exactly 403.7 mbsf. To obtain estimates of the parameters, we used linear interpolation to obtain a resistivity of $0.799 \mathrm{ohm}-\mathrm{m}$ and a porosity of $55.95 \%$. The calculated shape factor is thus 2.45 . However, the porosity values just above 403.7 mbsf are generally consistently in the $50 \%$ to $51 \%$ 
D. C. NOBES ET AL.

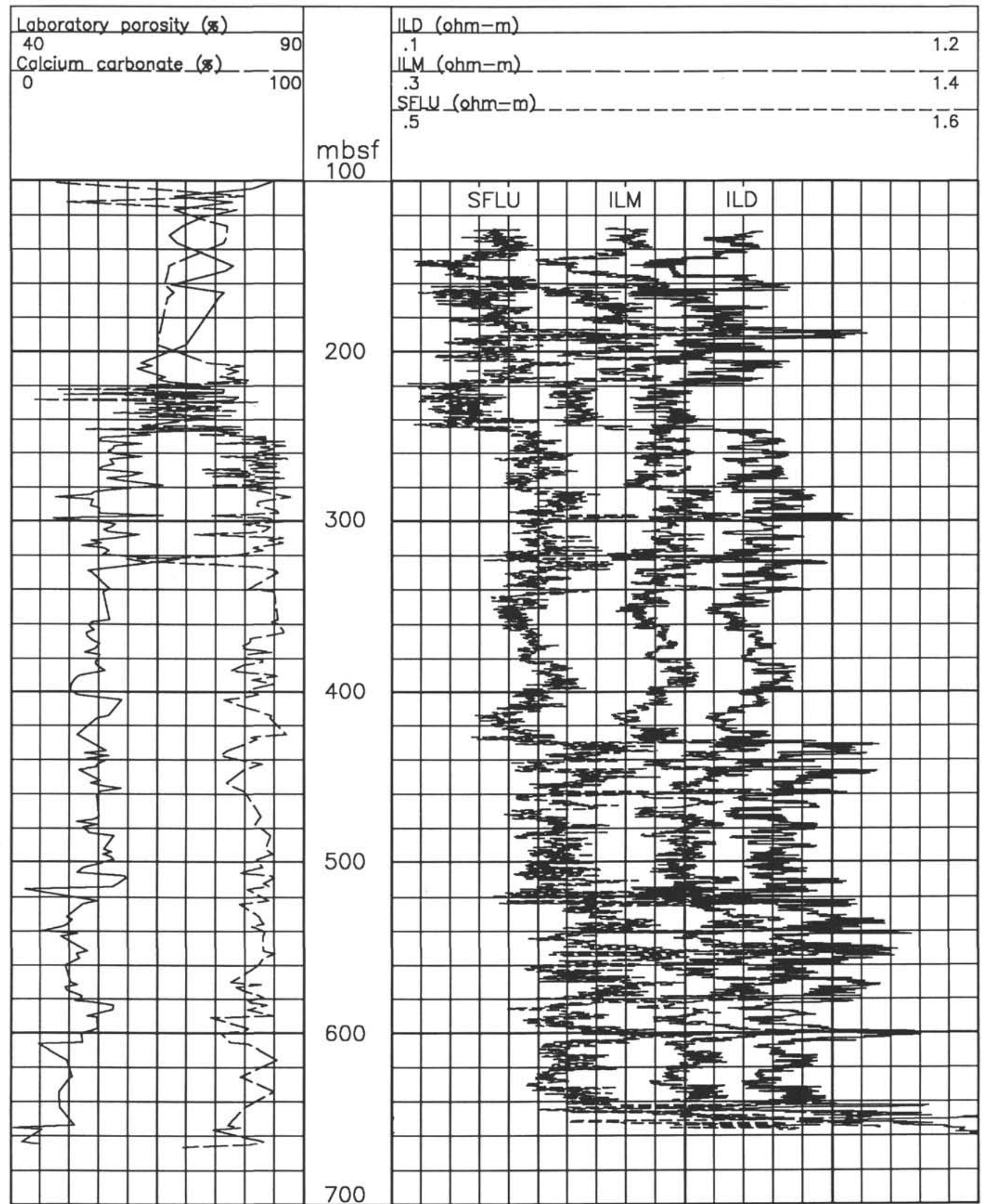

Figure 4. Plot of the raw resistivity and porosity data in standard American Petroleum Institute (API) format. The resistivities of the deep (ILD) and medium induction (ILM) logs and the shallow focused laterlog (SFLU) are plotted using offset scales for easier examination. The ILD and ILM, in particular, are quite similar. The carbonate content is plotted alongside the porosity. High porosity, low carbonate content, and low resistivity occur in the interval from 220 to $245 \mathrm{mbsf}$, an ash-bearing clayey diatom ooze. 
range, whereas the value of $58.92 \%$ at $403.7 \mathrm{mbsf}$ is significantly higher than the other porosity values in Hole 704B just above or below 403.7 mbsf. Thus the interpolated porosity value could be anomalously high. The conductivity also varies widely in this depth range, from a low of $0.78 \mathrm{ohm}-\mathrm{m}$ at 404.78 mbsf to a high of $0.82 \mathrm{ohm}-\mathrm{m}$ at $402.35 \mathrm{mbsf}$. If we use a porosity range of $50 \%$ to $54 \%$ and a resistivity range of 0.78 to $0.82 \mathrm{ohm}-\mathrm{m}$, then the shape factor falls in the range 2.02 to 2.35 .

At $481.7 \mathrm{mbsf}$, the pore-fluid resistivity is of the order of 0.187 ohm-m, but we cannot have any confidence in the temperature, and thus the pore-fluid resistivity, at this depth. On the other hand, the porosities and resistivities across this range are much more stable. At $481.7 \mathrm{mbsf}$, the interpolated porosity and resistivity are $53.1 \%$ and $0.845 \mathrm{ohm}-\mathrm{m}$, respectively. The calculated shape factor is 2.38 . The respective ranges of porosity and resistivity values are $52 \%$ to $53 \%$ and 0.83 to $0.87 \mathrm{ohm}-\mathrm{m}$. The shape factor range is then 2.27 to 2.45 .

The shape factor need not be constant with depth, but could, in principle, change as the sediment becomes more indurated and the resistivity becomes dominated by connected cracks and fractures. However, we will use a constant shape factor, for lack of control on its variation. We will use two extreme values of the shape factor, $n=2.0$ and 2.4 , to compute the temperature. We may then compare the overall derived temperature profiles with the measured values. We must emphasize that our procedure is inherently empirical.

Combining equations (1) and (2), we obtain an equation for computing the temperature from the porosity and resistivity at depths where we have no temperature measurements:

$$
T=10 / \rho \varphi^{\mathrm{n}}-10 / 3,
$$

where $\varphi$ is the decimal porosity, $\rho$ is the resistivity in ohm-m, and $T$ is the temperature in ${ }^{\circ} \mathrm{C}$. The porosity and resistivity were smoothed first, in order to remove some of the larger excursions and yield as smooth a temperature profile for the determination of the gradient as possible. The smoothed porosity, resistivity, and temperature profiles are shown in Figure 5. A shape factor of 2.4 yielded the higher temperature profile, which more closely agrees with the measured probe temperatures.

Using a shape factor of 2.4 , the best linear fit to the temperature profile yielded a gradient of $38 \mathrm{mK} / \mathrm{m}$; a gradient of $16 \mathrm{mK} / \mathrm{m}$ was obtained when a shape factor of 2.0 was used. These values cannot be directly compared, however. The temperature profile for $n=2.0$ ends at the top of Subunit ID; if we use the results for $n=2.4$ for Subunits ID, IIA, and IIB only, then the gradient is $29 \mathrm{mK} / \mathrm{m}$. The temperature values obtained for Subunit IC and higher in Hole 704B were small or even negative and are thus unreliable. Indeed the whole temperature profile for $n=2.0$ is much lower than the measured temperatures. We therefore conclude that the temperature curve for $n=2.4$ is the more reliable profile to use for estimation of the heat flow.

There are a number of distinct thermal units apparent when one examines the derived temperature profiles in Figure 5. The lithostratigraphic units shown on the right of the figure are in approximate correspondence with the thermal units. There are no conductivity log data for Subunit IA, and the porosity data are sparse for Subunit IB and the upper part of Subunit $\mathrm{IC}_{1}$. The temperature profile changes slowly with depth in Subunit IC, and again in Subunit IIA and the adjacent parts of Subunits ID and IIB. The principal gradient is in Subunits ID and IIB. We obtain significantly higher gradients if we use
Subunits ID and IIB $(n=2.4)$ gradients of 48 and $61 \mathrm{mK} / \mathrm{m}$, respectively, with an average of $54 \mathrm{mK} / \mathrm{m}$ for the two subunits, and 30 and $36 \mathrm{mK} / \mathrm{m}(n=2.0)$ with an average of 33 $\mathrm{mK} / \mathrm{m}$.

\section{THERMAL CONDUCTIVITY}

The thermal conductivity, $k$, is well represented using a geometric mean equation (Woodside and Messmer, 1961; Henderson and Davis, 1983) of the form

$$
k=k_{w}^{\varphi} \times k_{g}^{1-\varphi},
$$

where $k_{\mathrm{g}}$ is the thermal conductivity of water, with a value of about $0.6 \mathrm{~W} / \mathrm{m}-\mathrm{K}$, and $k_{\mathrm{g}}$ is the grain thermal conductivity. The sediments at Site 704 are carbonate rich, except in the upper part of the section, where there is an alternating sequence of siliceous and carbonaceous oozes. The carbonate grain thermal conductivity is $5.22 \mathrm{~W} / \mathrm{m}-\mathrm{K}$, and equation (5) provides a good representation of the dependence of the thermal conductivity on the porosity (Nobes, Mienert, and Dirksen, this volume).

The derived thermal-conductivity profile is shown along with the other profiles in Figure 5. Note that the changes in the temperature and thermal conductivity reflect the porosity variations, decreasing as the porosity increases and vice versa. Because the heat flow is computed as the product of the temperature gradient and the thermal conductivity, then any heat-flow profile would similarly reflect changes in the porosity. The thermal-conductivity profile could be labeled as a heat-flow profile with an appropriate change of scale. The thermal conductivity can be divided into the same thermal units as for the temperature. The overall mean thermal conductivity is $1.413 \pm 0.070 \mathrm{~W} / \mathrm{m}-\mathrm{K}$; the mean thermal conductivity over the range for which we have computed temperatures and the temperature gradient is $1.59 \pm 0.17 \mathrm{~W} / \mathrm{mK}$. For Subunits ID and IIB, the mean thermal conductivities are $1.566 \pm 0.06$ and $1.735 \pm 0.095 \mathrm{~W} / \mathrm{m}-\mathrm{K}$, respectively.

\section{HEAT-FLOW ESTIMATES AND DISCUSSION}

The heat flow is estimated using the computed best-fit temperature gradient and the average thermal conductivity. For the two direct temperature measurements, which were taken within Subunits IIA and IIB, the product of the gradient and the mean thermal conductivity over the interval yields a heat flow of $32 \pm 6 \mathrm{~mW} / \mathrm{m}^{2}$. If we use the gradient between the seafloor and $403.7 \mathrm{mbsf}$, we obtain a heat flow of $69 \mathrm{~mW} / \mathrm{m}^{2}$. The product of the temperature gradient derived from the resistivity and porosity with the thermal conductivity yields an average overall heat-flow estimate of $60 \pm 13 \mathrm{~mW} / \mathrm{m}^{2}$; if we use only the results for Subunits ID, IIA, and IIB, then the heat flow is $47.5 \pm 10 \mathrm{~mW} / \mathrm{m}^{2}$. Finally, if we use the temperature gradient derived using a shape factor of $n=2$, we obtain a heat-flow estimate of $25 \pm 6 \mathrm{~mW} / \mathrm{m}^{2}$. The latter heat-flow estimate and that obtained directly from the measured temperatures are similar, and because the temperatures derived from the resistivity and porosity using a shape factor of $n=2$ are well below the measured temperatures, we conclude that these estimates of the heat flow are too low.

The question remains, however, regarding which of the heat-flow estimates, $60 \pm 13 \mathrm{~mW} / \mathrm{m}^{2}$ or $47.5 \pm 10 \mathrm{~mW} / \mathrm{m}^{2}$, represents the correct heat flow. The higher heat flow is derived from a temperature gradient of $38 \mathrm{mK} / \mathrm{m}$, which when projected up to the seafloor yields a temperature of $3^{\circ} \mathrm{C}$; the projection of the other gradient yields a much higher temperature. The estimate for the seafloor temperature is of the order 


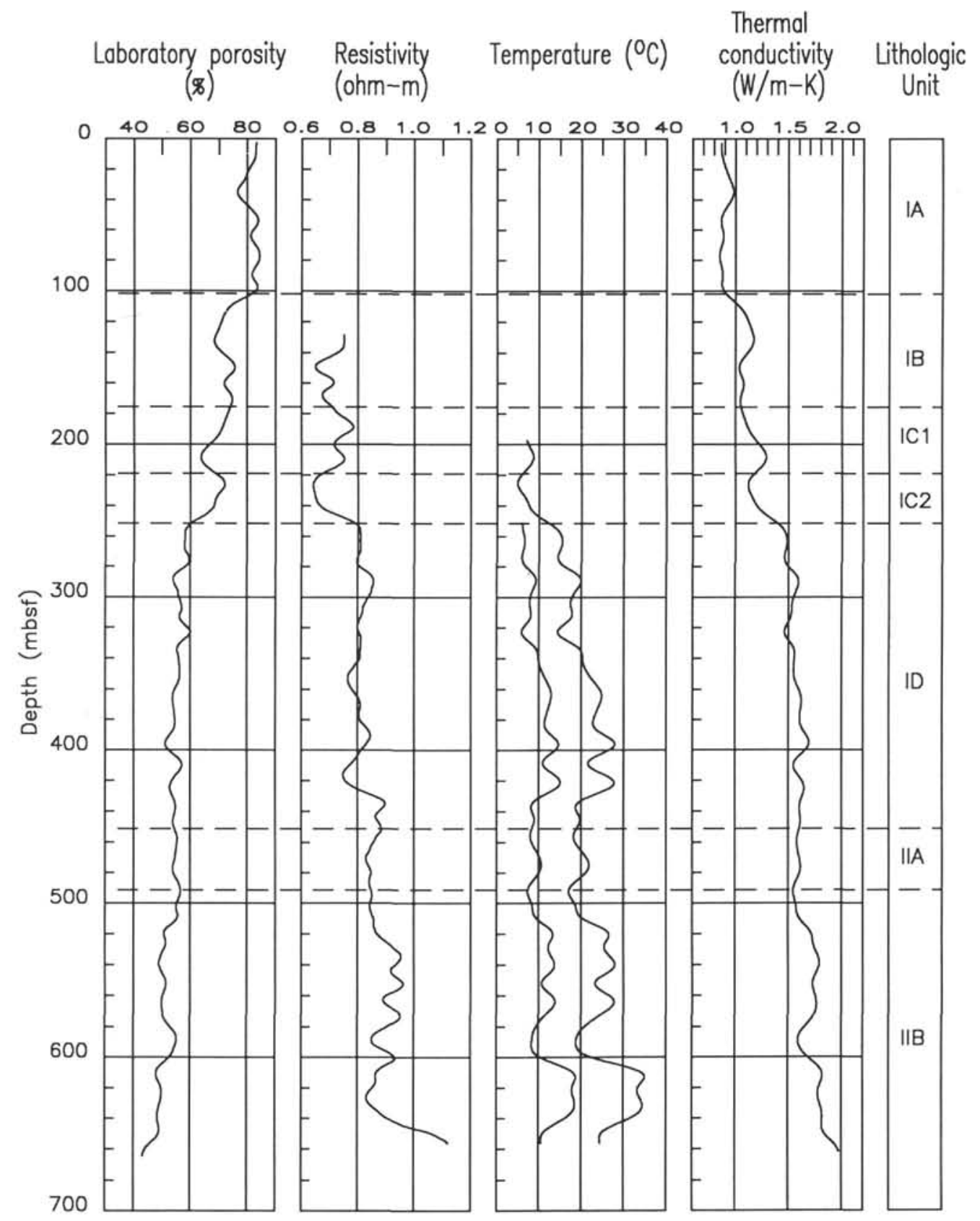

Figure 5. The smoothed profiles of laboratory-measured porosity, electrical resistivity, calculated temperature, and calculated thermal conductivity and the lithostratigraphic units, Hole 704B. The two temperature profiles represent the two extreme shape factors used in the modified Archie's law: the profile on the right, the higher temperature, was computed using $n=2.4$; the profile on the left, the lower temperature, was computed using $n=2.0$. The higher temperature profile is consistent with the temperatures measured using the Uyeda probe.

of $2^{\circ} \mathrm{C}$. In addition, if we assume that the temperature increases linearly with depth from the seafloor to $403.7 \mathrm{mbsf}$, we obtain a heat flow of $69 \mathrm{~mW} / \mathrm{m}^{2}$, within the error bounds of the result obtained using the temperature calculated from the resistivity and porosity. We accept the value of $60 \pm 13$ $\mathrm{mW} / \mathrm{m}^{2}$. We note, however, that the temperature gradient could increase near the seafloor and that the two estimates have a substantial overlap.

Given the estimated heat flow of $60 \pm 13 \mathrm{~mW} / \mathrm{m}^{2}$, how does that value compare with the heat flow that might be expected for oceanic crust of Late Cretaceous to early Paleocene age? Our results are almost identical to that obtained at DSDP Site $511,62 \mathrm{~mW} / \mathrm{m}^{2}$ (Langseth and Ludwig, 1983). The crust at Site 511 is slightly older; it lies on the edge of the Falklands Plateau and the Georgia Basin, to the west of the Islas Orcadas Rise, which is conjugate to the Meteor Rise. The error bounds on the heat flow do not allow us to perform any detailed interpretation at this point. We can only state that the heat flow is consistent with the age of the Meteor Rise. 


\section{CONCLUSIONS}

We have obtained an estimate of the heat flow using :mperatures derived from the resistivity and porosity through 1e use of a modified Archie's law. The temperature profile 'as calibrated using two temperature measurements from J3.7 and 481.7 mbsf in Hole 704B on the Meteor Rise. We btain an estimate of $60 \pm 13 \mathrm{~mW} / \mathrm{m}^{2}$ for the heat flow, a value lat is consistent with the age of the Meteor Rise and with the eat flow determined for a conjugate site of slightly greater age $\mathrm{n}$ the edge of the Falklands Plateau. We obtain a similar ssult of $69 \mathrm{~mW} / \mathrm{m}^{2}$ if we simply assume that the temperature radient is constant from the seafloor to $403.7 \mathrm{mbsf}$.

\section{ACKNOWLEDGMENTS}

DCN acknowledges the support of the Natural Sciences nd Engineering Research Council of Canada. The temperaire readings in Hole 704B were collected by "Trapper" Ieschleba. We thank Mr. Dirk Kassenaar of the University of Vaterloo for the use of his Viewlog program, which greatly ased the data analysis. R. D. Hyndman and M. G. Langseth rovided useful comments.

\section{REFERENCES}

oyce, R. E., 1976. Definitions and laboratory techniques of compressional sound velocity parameters and wet-water content, wet-bulk density and porosity parameters by gravimetric and gamma-ray attenuation techniques. In Schlanger, S. O., Jackson, E. D., et al., Init. Repts. DSDP, 33: Washington (U.S. Govt., Printing Office), 931-958.

rury, M. J., and Hyndman, R. D., 1979. The electrical resistivity of oceanic basalts. J. Geophys. Res., 84:4537-4545.

lenderson, J., and Davis, E. E., 1983. An estimate of the heat flow in the western North Atlantic at Deep Sea Drilling Project Site 534 In Sheridan, R. E., Gradstein, F. M., et al., Init. Repts. DSDP, 76: Washington (U.S. Govt. Printing Office), 719-724.
Hyndman, R. D., Langseth, M. G., and Von Herzen, R. P., 1987. Deep Sea Drilling Project geothermal measurements: a review. Rev. Geophys., 25:1563-1582.

Jackson, P. D., Taylor Smith, D., and Stanford, P. N., 1978. Resistivity-porosity-particle shape relationships for marine sands. Geophysics, 43:1250-1268.

Langseth, M. G., and Ludwig, W. J., 1983. A heat flow measurement on the Falkland Plateau. In Ludwig, W. J., Krasheninnikov, V. A., et al., Init. Repts. DSDP, 71: Washington (U.S. Govt. Printing Office), 299-303.

Mendelson, K. S., and Cohen, M. H., 1982. The effect of grain anisotropy on the electrical properties of sedimentary rocks. Geophysics, 47:257-263.

Nobes, D. C., Villinger, H., Davis, E. E., and Law, L. K., 1986. Estimation of marine sediment bulk physical properties at depth from seafloor geophysical measurements. J. Geophys. Res., 91:14033-14043.

Quist, A. S., and Marshall, W. L., 1968. Electrical conductances of aqueous sodium chloride solutions from 0 to $800^{\circ}$ and at pressures to 4000 bars. J. Phys. Chem., 72:684-703.

Shipboard Scientific Party, 1988a. Explanatory Notes. In Ciesielski, P. F., Kristoffersen, Y., et al., Proc. ODP, Init. Repts., 114: College Station, TX (Ocean Drilling Program), 3-22. , 1988b. Site 704. In Ciesielski, P. F., Kristoffersen, Y., et al., Proc. ODP, Init. Repts., 114: College Station, TX (Ocean Drilling Program), 621-795.

Woodside, W., and Messmer, J. H., 1961. Thermal conductivity of porous media. J. Appl. Phys., 32:1688-1699.

Yokota, I., Kinoshita, K., and Uyeda, S., 1979. New DSDP (Deep Sea Drilling Project) downhole temperature probe utilizing digital self-recording system with IC RAM elements. Bull. Earthquake Res. Inst., Univ. Tokyo, 54:441-462.

Date of initial receipt: 6 December 1988

Date of acceptance: 17 November 1989

Ms 114B-164 